\title{
Spermine alleviates heat-induced senescence in creeping bentgrass by regulating water and oxidative balance, photosynthesis, and heat shock proteins
}

\author{
L.L. LIANG ${ }^{+}$, Y.Q. CAO ${ }^{+}$, D. WANG, Y. PENG, Y. ZHANG, and Z. LI* \\ Department of Grassland Science, College of Animal Science and Technology, Sichuan Agricultural University, \\ Chengdu 611130, China
}

*Corresponding author: E-mail: lizhou1986814@163.com

\begin{abstract}
Spermine (SPM) is involved in response to abiotic stress in plants, but the potential role of SPM in regulating senescence has not been well documented. Objectives of this study were to examine the effect of changes in endogenous polyamines (PAs) by SPM application on improving heat tolerance of creeping bentgrass (Agrostis stolonifera) and explore the SPM-regulated senescence associated with alterations of water and oxidative balance, photosynthesis, and heat shock proteins under heat stress. The results showed that persistent high temperature caused severe oxidative damage and significant decreases in chlorophyll (Chl) content, photosynthetic efficiency, and leaf water content leading to premature senescence in creeping bentgrass, as reflected by a significant upregulation of transcriptions of senescenceassociated genes (AsSAG39, Ash36, and Asl20). The improvement of endogenous spermidine (SPD) and SPM content induced by SPM application could significantly alleviate heat stress damage to creeping bentgrass through maintaining higher Chl content, net photosynthetic rate, photochemical efficiency, and performance index on absorption basis, promoting osmotic adjustment ability and antioxidant enzyme (superoxid dismutase, catalase, peroxidase, and ascorbate peroxidase) activities to enhance the scavenging capacity of reactive oxygen species, and upregulating transcriptions of heat shock protein (HSP) genes (HSP90-5, HSP90.1-b1, HSP82, HSP70, HSP26.7, HSP17.8, and HSP12) helping to maintain normal synthesis and functions of proteins under high temperature stress, thereby delaying heat-induced leaf senescence. These findings reveal an important role of PAs in regulating senescence in perennial plants exposed to a high temperature environment.
\end{abstract}

Keywords: Agrostis stolonifera, antioxidants, osmotic adjustment, polyamines, reactive oxygen species, photochemical efficiency, thermotolerance.

\section{Introduction}

The typical symptom of high temperature damage to plants is accelerated leaf senescence, which is manifested in leaf chlorosis associated with the degradation of chlorophyll $(\mathrm{Chl})$ and the increase in membrane lipid peroxidation (Haba et al. 2014). Generally, the Chl degradation becomes faster than biosynthesis and a significant decline in photosynthesis could be attributed to destruction of chloroplast structures during senescence (Giles et al. 1976, Graham and Smith 1992). It has been found that heat-induced leaf senescence was mainly due

$\overline{\text { Received }} 14$ September 2020, last revision 4 February 2021, accepted 9 February 2021.

Abbreviations: APX - ascorbate peroxidase; C - control; C+SPM - control plus SPM application; CAT - catalase; Chl - chlorophyll; DM - dry mass; EL - electrolyte leakage; H - heat stress; H+SPM - heat stress plus SPM application; HPLC - high performance liquid chromatography; HSP - heat shock protein; FM - fresh mass; Fv/Fm - photosystem II maximum quantum yield efficiency; LSD - least significant difference; MDA - malondialdehyde; OP - osmotic potential; PAs - polyamines; PGRs - plant growth regulators; $\mathrm{P}_{\mathrm{N}}$ - net photosynthetic rate; PIABS - performance index on absorption basis; POD - peroxidase; PUT - putrescine; ROS - reactive oxygen species; qPCR - quantitative polymerase chain reaction; RWC - relative water content; SOD - superoxide dismutase; SPD - spermidine; SPM - spermine; Tm - melting temperature; WUE - water use efficiency; WSM - water saturated mass.

Acknowledgements: This research was supported by the National Natural Science Foundation of China (Grant No. 31702182).

${ }^{+}$These authors contributed equally.

Conflict of interest: The authors declare that they have no conflict of interest. 
to the increase in Chl degradation, but not significantly related to the change of Chl synthesis in bentgrass species (Jespersen et al. 2016). High temperature breaks down the homeostasis of reactive oxygen species (ROS) and causes their immense accumulation leading to oxidative damage to cell membranes, proteins, and Chl (Camejo et al. 2005, Zhu and Shen 2014). Previous studies have proved that enhanced antioxidant system induced by phytohormones or plant growth regulators (PGRs) such as cytokinins, salicylic acid, and melatonin could effectively alleviate stress-induced senescence in grass and other plant species (Jibran et al. 2013, Zhang et al. 2017, 2019). In addition, heat stress induces accumulation of heat shock proteins (HSPs), which is an important adaptive response to high temperature in plants. HSPs can be classified into six subclasses, including HSP100, HSP90, HSP70, HSP60, HSP40, and small HSPs (sHSPs, molecular mass between 12 to $42 \mathrm{kDa}$ ). These HSPs as molecular chaperones exhibit similar or different function of preventing proteins aggregation, assisting in refolding of denatured proteins, and stabilizing abnormal proteins when plants suffer from abiotic stress (Timperio et al. 2008). HSPs-regulated senescence has been reported in animals. However, the relationship between HSPs expression and leaf senescence has not been well demonstrated in plants.

Polyamines (PAs) as nitrogenous compounds with high biological activity are widely found in both prokaryotes and eukaryotes. Putrescine (PUT), spermidine (SPD), and spermine (SPM) are three major PAs in higher plants. PAs not only regulate plant growth, maturation, and fruit development (Moskova et al. 2014), but also play an important role in promoting stress tolerance in plants (Perez-Amador et al. 2002). The study by Shukla et al. (2015) found that foliar application of PAs has a low effect on water relations, but protects photosynthetic and cellular membranes in creeping bentgrass (Agrostis stolonifera) subjected to drought stress. It has been reported that PAs could promote Chl fluorescence or antioxidant capacity contributing to improved heat tolerance in tomato plants or rice seedlings (Murkowski 2001, Mostofa et al. 2014). Application of SPD reduced the harmful effects in pea during a rapid increase in temperature (Todorova et al. 2016). However, SPM-regulated senescence associated with alterations of oxidative balance, photosynthesis, and heat shock proteins has not been well documented in plants under heat stress.

Creeping bentgrass is a perennial turfgrass adapted to the cold and humid climate with the optimum temperature for the growth between $15-20^{\circ} \mathrm{C}$ (Kubik et al. 2011). When the ambient temperature is higher than $25^{\circ} \mathrm{C}$, the growth of creeping bentgrass is inhibited and the occurrence of diseases and insect pests is increased. High temperature has become a critical factor in restricting its growth and turf quality. Objectives of this study were to examine the effect of exogenous SPM on improving heat tolerance of creeping bentgrass by inducing changes of endogenous PAs, and further to explore the SPM-regulated senescence associated with alterations of water and oxidative balance, photosynthesis, and heat shock proteins expression in creeping bentgrass under heat stress.

\section{Materials and methods}

Plants and treatments: Creeping bentgrass (Agrostis stolonifera L. cv. Penncross) seeds were evenly sown $\left(6 \mathrm{~g} \mathrm{~m}^{-2}\right)$ and then germinated in seedling-raising plates $(20 \times 14.5 \times 6 \mathrm{~cm})$. Seeds were purchased from Tee-2Green Corporation (Hubbard, OR, USA). Sterilized quartz sand was used as a cultivation medium. After $8 \mathrm{~d}$ of germination in distilled water, seedlings were watered with Hoagland's solution (Hoagland and Arnon 1950) for $20 \mathrm{~d}$ in a controlled growth chamber under $23 / 19{ }^{\circ} \mathrm{C}$ day/ night temperatures, a 14-h photoperiod, an irradiance of $750 \mu \mathrm{mol}$ of photosynthetically active radiation (PAR) $\mathrm{m}^{-2} \mathrm{~s}^{-1}$, and a $70 \%$ relative humidity. Plants 28 -d-old were divided into four groups: 1) $\mathrm{C}$, control plants cultivated in an optimum temperature $\left(23 / 19^{\circ} \mathrm{C}\right)$ for $\left.30 \mathrm{~d} ; 2\right) \mathrm{C}+\mathrm{SPM}$, plants pretreated with $0.1 \mathrm{mM}$ SPM for $2 \mathrm{~d}$ and then cultivated in normal Hoagland's solution without SPM for $28 \mathrm{~d}$ in an optimum temperature $\left.\left(23 / 19^{\circ} \mathrm{C}\right) ; 3\right) \mathrm{H}$, heat stress: plants were cultivated in an optimum temperature $\left(23 / 19^{\circ} \mathrm{C}\right)$ for $2 \mathrm{~d}$ and then moved into a high temperature growth chamber $\left(38 / 27^{\circ} \mathrm{C}\right)$ for $\left.28 \mathrm{~d} ; 4\right) \mathrm{H}+\mathrm{SPM}$ plants were pretreated with $0.1 \mathrm{mM}$ SPM in an optimum temperature $\left(23 / 19^{\circ} \mathrm{C}\right)$ for $2 \mathrm{~d}$ and then moved into a high temperature $\left(38 / 27^{\circ} \mathrm{C}\right)$ for $28 \mathrm{~d}$. Each treatment had four independent replicates and plant materials were randomly placed in growth chambers during the experiment. Leaves of plants were sampled on $0,7,14,21$, and 28 day for the determination of physiological parameters and genes expressions.

The measurement of endogenous PAs: Endogenous PAs content was determined by high performance liquid chromatography (HPLC, Agilent-1200, Agilent Technologies, Santa Clara, USA). Fresh leaves (0.2 g) were homogenized with $2 \mathrm{~cm}^{3}$ of $5 \%(\mathrm{v} / \mathrm{v})$ cold perchloric acid and incubated at $4{ }^{\circ} \mathrm{C}$ for $1 \mathrm{~h}$. The homogenate was centrifuged at $10000 \mathrm{~g}$ and $4{ }^{\circ} \mathrm{C}$ for $30 \mathrm{~min}$ and the supernatant was collected for benzoylation. The $500 \mathrm{~mm}^{3}$ of supernatant were added into the reaction solution ( $2 \mathrm{~cm}^{3}$ of $2 \mathrm{M} \mathrm{NaOH}$ and $10 \mathrm{~mm}^{3}$ of benzoyl chloride) and then the mixture was incubated at $37^{\circ} \mathrm{C}$ for $30 \mathrm{~min}$. The saturated $\mathrm{NaCl}$ solution $\left(2 \mathrm{~cm}^{3}\right)$ and cold diethyl ether $\left(2 \mathrm{~cm}^{3}\right)$ was added and then mixed uniformly. The supernatant of ether phase $\left(1 \mathrm{~cm}^{3}\right)$ was evaporated to dryness and then redissolved in $1 \mathrm{~cm}^{3}$ of methanol. PAs extract $\left(20 \mathrm{~mm}^{3}\right)$ was added to a reversed-phase Tigerkin C18 column $(150 \mathrm{~mm} \times 4.6 \mathrm{~mm}, 5 \mu \mathrm{m}$ particle size $)$ with a column temperature of $25^{\circ} \mathrm{C}$. Methanol- $\mathrm{H}_{2} \mathrm{O}(64: 36, \mathrm{v} / \mathrm{v})$ was used as the mobile phase. Peaks of PAs were observed at $254 \mathrm{~nm}$ with a flow rate of $1 \mathrm{~cm}^{3} \mathrm{~min}^{-1}$ by UV detector (Ramos et al. 2014).

The measurement of chlorophyll content and photosynthesis: For determination of $\mathrm{Chl}$ content, $0.1 \mathrm{~g}$ of fresh leaves were immersed in a $10 \mathrm{~cm}^{3}$ of the solution containing $80 \%$ acetone and $95 \%$ ethanol $(1: 1, v / v)$ and placed in the dark until all leaves faded to white. The extract solution was measured at 663 and $645 \mathrm{~nm}$ in a spectrophotometer (Spectronic Instruments, 
Rochester, USA) (Arnon 1949). Net photosynthesis rate $\left(\mathrm{P}_{\mathrm{N}}\right)$ and water use efficiency (WUE) of 10 individual leaves per replicate per treatment were measured with a photosynthetic apparatus $\left(C I R A S^{-3}, P P\right.$ Systems, Norfolk, UK). Leaves were placed in the leaf chamber that provided $400 \mathrm{~mm}^{3} \mathrm{dm}^{-3} \mathrm{CO}_{2}$ and $800 \mu \mathrm{mol} \mathrm{m} \mathrm{m}^{-2}$ of red and blue radiation. For measurements of photosystem II maximum quantum yield efficiency $\left(\mathrm{F}_{\mathrm{v}} / \mathrm{F}_{\mathrm{m}}\right)$ and performance index on absorption basis (PIABS), the data was recorded with a fluorometer (Pocket PEA, Hansatech, Norfolk, UK) after leaves were adapted to darkness for $30 \mathrm{~min}$ by using the leaf clips.

The measurement of reactive oxygen species and antioxidant enzyme activities: The measurements of generation rate of superoxide anion $\left(\mathrm{O}_{2}^{--}\right)$, hydrogen peroxide $\left(\mathrm{H}_{2} \mathrm{O}_{2}\right)$ content, or electrolyte leakage (EL) were conducted by using the method of Elstner and Heupel (1976), Velikova et al. (2000), or Blum and Ebercon (1981), respectively. The malondialdehyde (MDA) content, superoxide dismutase (SOD) activity, peroxidase (POD) activity, catalase (CAT) activity, or ascorbate peroxidase (APX) activity were determined by using the method of Dhindsa (1981), Giannopolitis and Ries (1977), Chance and Maehly (1955), or Nakano and Asada (1980), respectively. Specific methods for the determination of all above parameters have been reported in details in our previous study (Li et al. 2016).

The measurement of water status and total soluble sugars: Leaf relative water content (RWC) was determined from fresh mass (FM), dry mass (DM), and water saturated mass (WSM) according to the formula: RWC [\%] = $[(\mathrm{FM}-\mathrm{DM}) /(\mathrm{WSM}-\mathrm{DM})] \times 100$ (Barrs and Weatherley 1962). For osmotic potential (OP), $0.1 \mathrm{~g}$ of fresh leaves was immersed in $35 \mathrm{~cm}^{3}$ distilled water for $12 \mathrm{~h}$. The water-saturated leaves were immediately frozen in liquid nitrogen for $10 \mathrm{~min}$ and then thawed completely at $4{ }^{\circ} \mathrm{C}$. The osmolarity (c) of the cell sap in leaf was measured using a sampling chamber of osmometer (Wescor, Logan, USA). The OP [MPa] was calculated as $-\mathrm{c} \times 2.58 \times 10^{-3}$. For total soluble sugar, $0.02 \mathrm{~g}$ of dry leaf samples and $4 \mathrm{~cm}^{3}$ ethanol were mixed together and subjected to $80{ }^{\circ} \mathrm{C}$ water bath for $40 \mathrm{~min}$. After being centrifuged at $10000 \mathrm{~g}$ for $15 \mathrm{~min}$, the supernatant was collected. The activated carbon $(0.05 \mathrm{~g})$ was added to $2 \mathrm{~cm}^{3}$ of supernatant. The mixture was heated in a $80{ }^{\circ} \mathrm{C}$ water bath for $30 \mathrm{~min}$ and then filtered through a double-layer filter paper into a beaker. The filtrate $\left(0.2 \mathrm{~cm}^{3}\right)$ was added into $1 \mathrm{~cm}^{3}$ of anthrone reagent consisting of $1 \mathrm{~g}$ anthrone and $1 \mathrm{dm}^{3} \quad 80 \%$ sulfuric acid. The mixture was boiled in a $100{ }^{\circ} \mathrm{C}$ water bath for $1 \mathrm{~min}$ and then cooled to room temperature. The absorbance of reaction solution was measured at $625 \mathrm{~nm}$ (Bian et al. 2002).

Genes expression analyses: Gene relative expressions were performed using the real-time quantitative polymerase chain reaction (qPCR). For senescence-associated genes (AsSAG39, Ash36, and Asl20) and heat shock protein genes (HSP90-5, HSP90.1-b1, HSP82, HSP70, HSP26.7,
HSP 17.8, or HSP12), total RNA extraction and cDNA firststrand synthesis were obtained by using HiPure universal RNA kit (Magen, Guangzhou, China) and Arevert Aid first strand cDNA synthesis kit (Fermentas, Vilnius, Lithuania), respectively. The gene expressions were determined using the $i$ Cycler $i Q$ qPCR detection system with SYBR Green Supermix (Bio-Rad, Hercules, USA). Genes reaction procedures were: $95{ }^{\circ} \mathrm{C}$ for $5 \mathrm{~min}$ and denaturation at $95{ }^{\circ} \mathrm{C}$ for $15 \mathrm{~s}$ (40 repeats), annealing at $58-64{ }^{\circ} \mathrm{C}$ for $45 \mathrm{~s}$, and then heating the amplicon from 60 to $95^{\circ} \mathrm{C}$ to obtain the melting curve. Gene primers and melting temperature (Tm) are shown in Table 1 Suppl. The $\beta$-Actin was used as the internal control. The relative expression of the target gene was calculated according to the formula $2^{-\Delta \Delta \mathrm{Ct}}$ (Livak and Schmittgen 2001).

Statistical analysis: The data was analyzed by using SPSS 20 (IBM, Armonk, NY, USA). The significant differences among $\mathrm{C}, \mathrm{C}+\mathrm{SPM}, \mathrm{H}$, and $\mathrm{H}+\mathrm{SPM}$ treatments were tested (ANOVA) based on the least significant difference (LSD) at $P \leq 0.05$.

\section{Results}

The SPM pretreatment significantly alleviated the growth inhibition of creeping bentgrass under heat stress (Fig. 1A). As compared with the optimum temperature treatments $(\mathrm{C}$ and $\mathrm{C}+\mathrm{SPM})$, high temperature treatments ( $\mathrm{H}$ and $\mathrm{H}+\mathrm{SPM}$ ) had significantly higher endogenous SPD and SPM content, but there were no significant differences in PUT content among four treatments (Fig. 1B). SPD and SPM content in the SPM-pretreated plants increased by 56.13 and $66.08 \%$ than unpretreated plants under heat stress, respectively (Fig. $1 B$ ). The expressions of senescence-associated genes AsSAG39, Ash36, and Asl20 in leaves were not significantly affected by SPM pretreatment under optimum temperature condition, but the expressions of these genes significantly increased under high temperature stress (Fig. 2). The expressions of $A s S A G 39$, Ash 36, and Asl20 in only heat treatment were $3.15,1.92$, and 1.39 times higher than those in $\mathrm{H}+\mathrm{SPM}$ treatment, respectively (Fig. 2). Heat stress led to significant declines in content of $\mathrm{Chl} a, \mathrm{Chl} b$, and total Chl, and in $\mathrm{P}_{\mathrm{N}}$ in leaves of SPM-pretreated and untreated plants (Fig. 3). Exogenous SPM pretreatment effectively alleviated heat-induced declines in $\mathrm{Chl}$ content and $\mathrm{P}_{\mathrm{N}}$ on $14^{\text {th }}$ and $28^{\text {th }}$ day (Fig. 3). In addition, $F_{v} / F_{m}$ and PIABS decreased continuously due to heat stress, and the H+SPM treatment showed significantly higher $F_{v} / F_{m}$ and PIABS than the $\mathrm{H}$ treatment on $14^{\text {th }}, 21^{\text {th }}$, and $28^{\text {th }}$ day (Fig. 4).

High temperature stress resulted in significant increases in the generation rate of $\mathrm{O}_{2}-\mathrm{H}_{2} \mathrm{O}_{2}$ content, and MDA content in leaves. As compared with $\mathrm{H}$ treatment, the $\mathrm{H}+\mathrm{SPM}$ treatment maintained a $36.23,45.35$, or $27.86 \%$ decrease in the generation rate of $\mathrm{O}_{2}^{-}, \mathrm{H}_{2} \mathrm{O}_{2}$, or MDA content, respectively (Fig. $5 A-C$ ). Similarly, the $\mathrm{H}+\mathrm{SPM}$ treatment could maintain significantly lower EL than the $\mathrm{H}$ during heat stress (Fig. $5 D$ ). The EL in the H+SPM decreased by 27.85 and $28.45 \%$ than that in the $\mathrm{H}$ on $14^{\text {th }}$ 
and $28^{\text {th }}$ day (Fig. 5D). Heat stress significantly increased SOD and APX activities, but decreased CAT and POD activities in SPM-treated and untreated plants (Fig. 6). The SOD, CAT, APX, or POD activities in the H+SPM treatment increased by $38.96,50.33,89.05$, or $22.12 \%$ in comparison to that in the $\mathrm{H}$ treatment, respectively (Fig. 6).

During heat stress, the leaf RWC and WUE decreased gradually, and the SPM-pretreated plants maintained significantly higher RWC and WUE at 14 and $28 \mathrm{~d}$ of heat stress (Fig. 7A,B). The RWC and WUE in H+SPM were higher by 17.50 and $80.39 \%$ as compared to that in the $\mathrm{H}$ on the $28^{\text {th }}$ day (Fig. $7 A, B$ ). The OP significantly declined, while total soluble sugar content significantly increased during high temperature stress (Fig. 7C,D). SPM-pretreated plants had 8.70 and $20.54 \%$ decreased OP as well as 20.10 and $11.18 \%$ increased content of total soluble sugar than untreated plants at 14 and $28 \mathrm{~d}$ of heat stress, respectively (Fig. 7C,D).

Genes expressions of HSPs were upregulated significantly by heat stress (Fig. 8). Expressions of HSP70, HSP 26.7, and HSP17.8 were higher than the expressions of HSP90-5, HSP90.1-b1, HSP82, and HSP12 in both of SPM-pretreated and untreated plants under high temperature stress. Under control conditions, the SPM pretreatment had no significant effects on HSP905, HSP90.1-b1, HSP82, HSP70, HSP26.7, HSP17.8, and HSP12 (Fig. 8). The expressions of HSP90-5, HSP90.1-b1, HSP82, HSP70, HSP26.7, HSP17.8, or HSP12 in H+SPM treatment increased by 91.96, 95.40, 143.98, 172.76, $202.01,80.62$, or $48.28 \%$ as compared to those in the $\mathrm{H}$ treatment, respectively (Fig. 8). Fig. 1 Suppl. shows integrated metabolic pathways of antioxidant, senescence, water balance, and heat shock response regulated by SPD in leaves of creeping bentgrass under heat stress.

\section{Discussion}

Changes of endogenous SPD and SPM content play important roles in regulating tolerance to abiotic stresses in plants. For example, exogenous SPD increases endogenous PAs content and enhances the tolerance of Kentucky bluegrass and Zoysiagrass to salt stress (Puyang et al. 2016, Li et al. 2017). Exogenous SPD effectively alleviates drought damage to creeping bentgrass associated with significant increases in endogenous SPD and SPM in leaves ( $\mathrm{Li}$ et al. 2015a). On the contrary, an Arabidopsis mutant with insufficient SPM biosynthesis shows hypersensitivity to salt and drought stress, but a SPM application alleviates stress damage in the mutant (Yamaguchi et al. 2006, Kusano et al. 2007). In the current study, SPM pretreatment further increased heatinduced increases in endogenous SPD and SPM, which was associated with enhanced thermotolerance in creeping bentgrass, as reflected by morphological and physiological changes. Transcriptions of senescence-associated genes supported that SPM treatment slowed down heat-induced leaf senescence, since SPM pretreatment significantly decreased heat-induced upregulation of AsSAG39, Ash36,

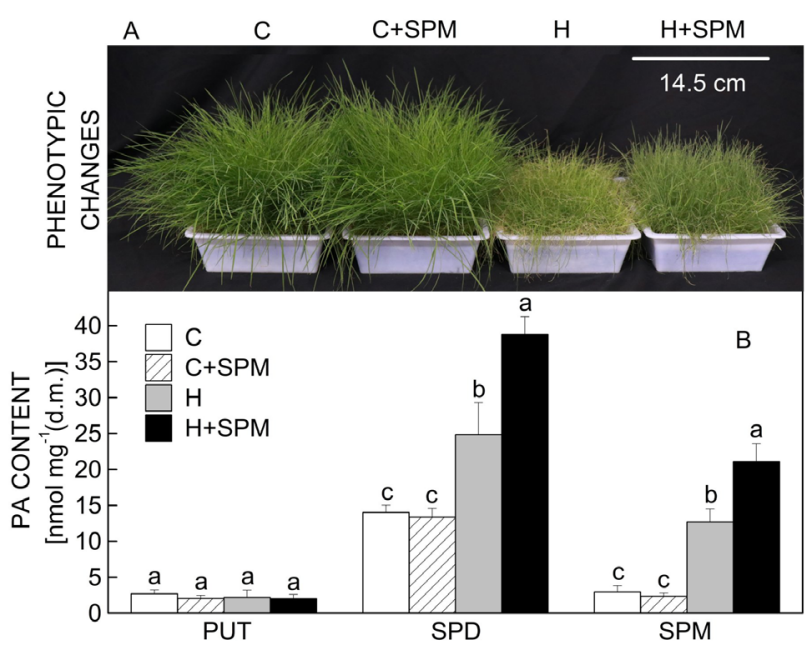

Fig. 1. Phenotypic changes $(A)$ and endogenous polyamine (PA) content including putrescine (PUT), spermidine (SPD) and spermine $(\mathrm{SPM})(B)$ in leaves of creeping bentgrass on $28^{\text {th }} \mathrm{d}$. Means \pm SEs, $n=4$. Different letters above columns indicate significant differences among treatments based on the least significant difference at $P \leq 0.05$. C - control, $\mathrm{C}+\mathrm{SPM}$ - control plus SPM application, $\mathrm{H}$ - heat stress, $\mathrm{H}+\mathrm{SPM}$ - heat stress plus SPM application.

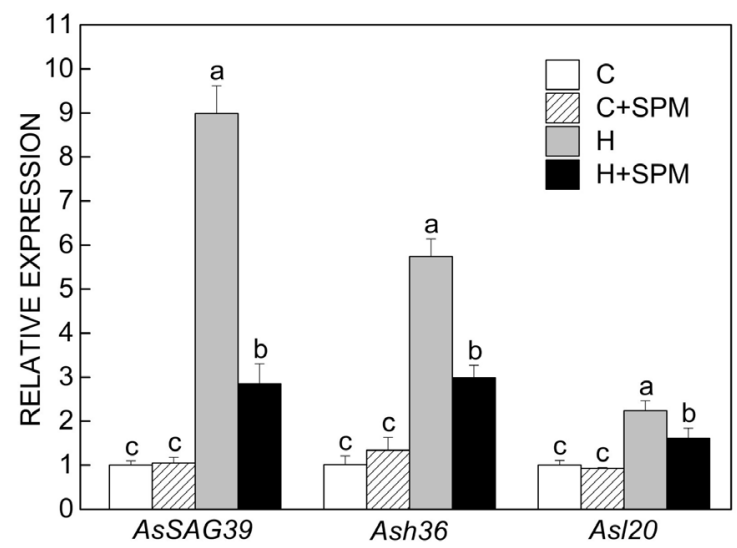

Fig. 2. Relative expressions of senescence-associated genes in leaves of creeping bentgrass on $28^{\text {th }} \mathrm{d}$. Means \pm SEs, $n=4$. Different letters indicate significant differences among treatments based on the least significant difference at $P \leq 0.05$. C - control, $\mathrm{C}+\mathrm{SPM}$ - control plus SPM application, $\mathrm{H}$ - heat stress, $\mathrm{H}+\mathrm{SPM}$ - heat stress plus SPM application.

and Asl20 expressions in leaves of creeping bentgrass. It is generally accepted that leaf senescence leads to photoinhibition, decline in Chl content, and destruction of chloroplast structure (Kumar et al. 2012). Current study found that the Chl content, $\mathrm{P}_{\mathrm{N}}, \mathrm{F}_{\mathrm{v}} / \mathrm{F}_{\mathrm{m}}$, and PIABS in leaves of SPM-treated creeping bentgrass were significantly higher than those of untreated plants during heat stress, indicating that the leaf senescence was alleviated by SPM. Similar results were found in the study of Hamdani et al. (2011) who reported that application of SPM protects photosynthetic apparatus under photoinhibitory conditions.

High temperature causes ROS accumulation resulting in cell compounds oxidation and membrane damage, which is one of the main causes of accelerated senescence 


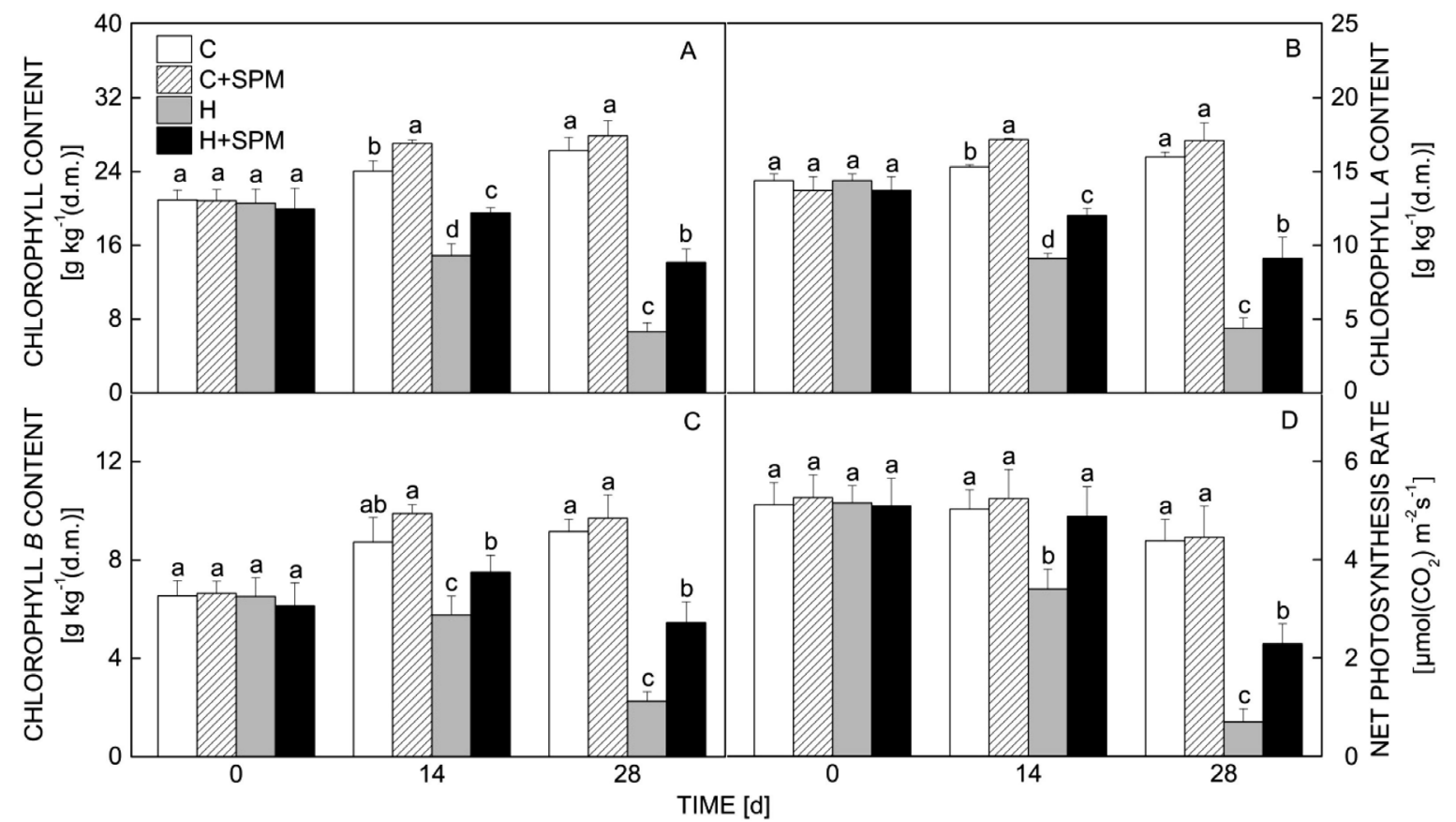

Fig. 3. Changes in total chlorophyll $(A)$, chlorophyll $a(B)$, chlorophyll $b(C)$ content, and net photosynthesis rate $(D)$ in leaves of creeping bentgrass during heat stress. Means \pm SEs, $n=4$. Different letters indicate significant differences among treatments based on the least significant difference $(P \leq 0.05)$ on a given day. $\mathrm{C}$ - control, $\mathrm{C}+\mathrm{SPM}$ - control plus SPM application, $\mathrm{H}-$ heat stress, H+SPM - heat stress plus SPM application.

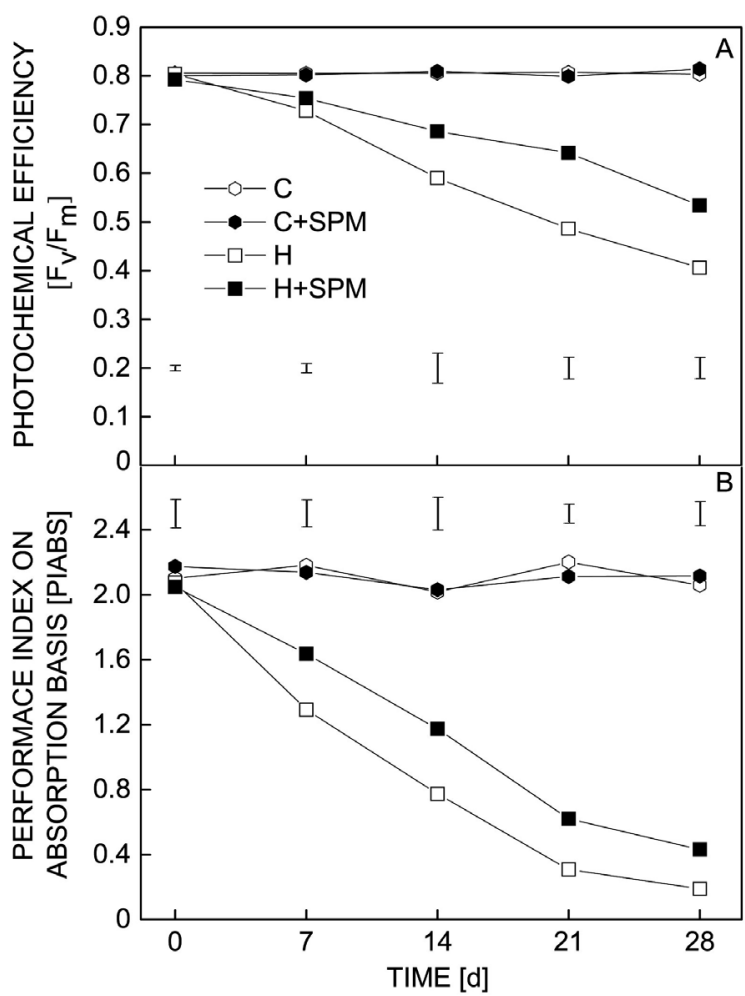

Fig. 4. Changes in photosystem II maximum quantum yield efficiency $(A)$ and performance index on absorption basis $(B)$ in leaves of creeping bentgrass during heat stress. Means \pm SEs, $n=4$. Vertical bars indicate least significance difference (LSD, $P \leq 0.05)$ values on a given day. $\mathrm{C}$ - control, $\mathrm{C}+\mathrm{SPM}$ - control plus SPM application, $\mathrm{H}$ - heat stress, $\mathrm{H}+\mathrm{SPM}$ - heat stress plus SPM application. in plants (Gill and Tuteja 2010). Significant increases in $\mathrm{O}_{2}^{--}, \mathrm{H}_{2} \mathrm{O}_{2}, \mathrm{MDA}$, and $\mathrm{EL}$ indicate oxidative damage to cells. However, SPM pretreatment was beneficial to the enhancement of SOD, CAT, POD, and APX activities in creeping bentgrass, which improved the scavenging ability of ROS to maintain cell membrane stability under heat stress. Similarly, SPM application improves SOD and CAT activities in pea plants associated with the mitigation of heat-induced oxidative damage and $\mathrm{Chl}$ degradation (Todorova et al. 2016). The drought-tolerant tomato cultivar Zarina has higher SPM content, SOD, and CAT activities than drought-sensitive cv. Josefina and also shows better tolerance to dehydration-induced oxidative stress (Sanchez-Rodriguez et al. 2016). SPM-pretreated mung bean seedlings maintains significantly higher SOD and CAT activities, helping to reduce ROS accumulation under combined heat and drought stress (Nahar et al. 2017). These studies together with our present findings indicated that the improvement in antioxidant defense and decline in oxidative damage were important regulatory mechanisms of SPM-alleviated senescence during heat stress.

In addition to antioxidant defense system, the maintenance of water balance is also important for plants to conquer high temperature environment due to the critical role of water balance in photosynthesis and ROS accumulation (Tsukaguchi et al. 2005). Heat-induced water loss in consequence of the imbalance between water uptake and transpiration accelerates plant senescence. Fu et al. (2014) found that SPM pretreatment effectively retards leaf wilting and water loss in trifoliate orange under a combined drought and heat stress. Applications of PAs prevent water loss through inducing stomatal 


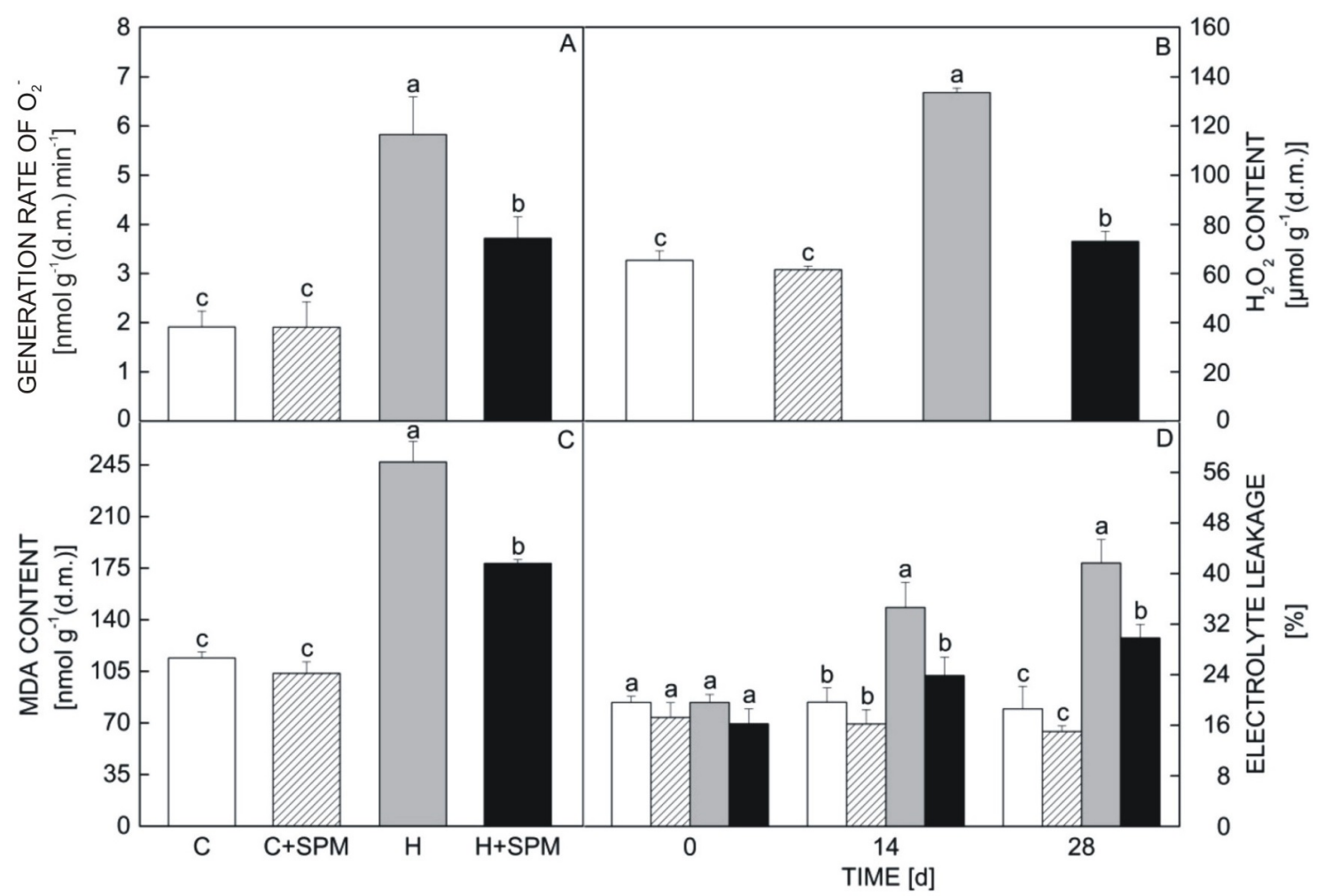

Fig. 5. Changes in the generation rate of $\mathrm{O}_{2}{ }^{-}(A), \mathrm{H}_{2} \mathrm{O}_{2}$ content $(B)$, and malondialdehyde (MDA) content $(C)$ in leaves of creeping bentgrass on $28^{\text {th }} \mathrm{d}$ and electrolyte leakage (D) in leaves of creeping bentgrass during heat stress. Means \pm SEs, $n=4$. Different letters above columns indicate significant differences among treatments based on the least significant difference $(P \leq 0.05)$ on a given day. C control, C+SPM - control plus SPM application, H - heat stress, H+SPM - heat stress plus SPM application.

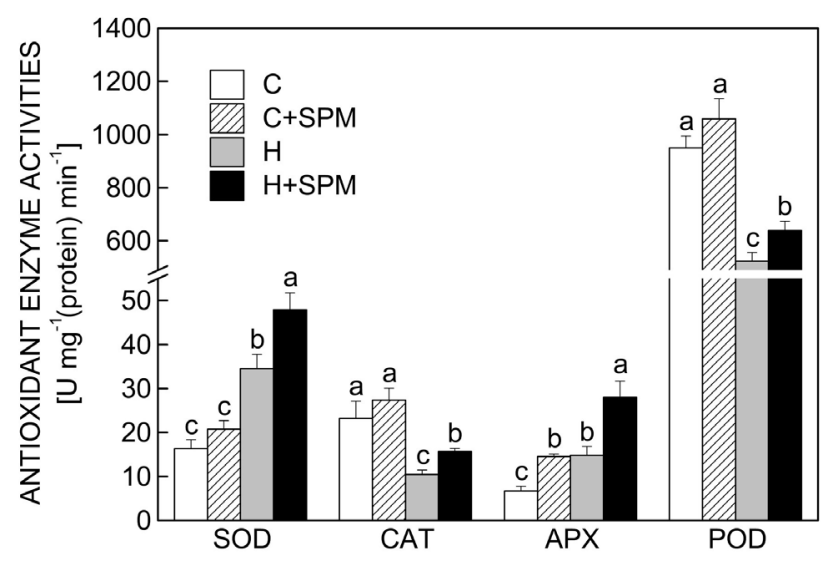

Fig. 6. Changes in superoxide dismutase (SOD), catalase (CAT), ascorbate peroxidase (APX), and peroxidase (POD) activities in leaves of creeping bentgrass on $28^{\text {th }} \mathrm{d}$. Means \pm SEs, $n=4$. Different letters above columns indicate significant differences among treatments based on the least significant difference at $P \leq 0.05$. C - control, C+SPM - control plus SPM application, $\mathrm{H}$ - heat stress, $\mathrm{H}+\mathrm{SPM}$ - heat stress plus SPM application.

closure in Arabidopsis under drought stress (Yamaguchi et al. 2007). Better maintenance of water homeostasis in white clover could be regulated by SPM associated with the accumulation of total soluble sugar, sucrose, and fructose under water stress ( $\mathrm{Li}$ et al. 2015b). However, a lack of study reports osmotic adjustment and water balance maintenance regulated by SPM when plants suffer from heat-induced senescence. In this study, heat stress significantly decreased RWC, WUE, and OP, but increased total soluble sugar content in leaves. Importantly, SPMpretreated creeping bentgrass maintained significantly higher RWC, WUE, and total soluble sugar as well as lower OP than untreated plants during heat stress. The results indicated that positive effects of SPM on regulating water homeostasis could be related to soluble sugar accumulation leading to a decline in OP under heat stress, which contributed to the slowing senescence during heat stress.

When plants respond to heat stress, HSPs quick synthesis and accumulation are positively related to the heat tolerance (Haslbeck 2002, Schramm et al. 2006, Huang and $\mathrm{Xu}$ 2008). Main functions of different HSPs have been identified in plants, such as $H S P 90$ for promoting proteins folding and assembly, HSP70 for preventing proteins aggregation and assisting in refolding, and small HSPs for stabilizing abnormal proteins under stress environments. Previous study found that enhanced tolerance against heat stress could be acquired by an OSHSP26 overexpression in tall fescue (Kim et al. 2012). Overexpression of HSP17.8 in Arabidopsis or HSP16.9 in tobacco enhance heat tolerance associated with increases in POD, CAT, and SOD activities and a decline in oxidative damage (Jiang et al. 2009, Sun et al. 2012). An $\gamma$-aminobutyric acid pretreatment can further improve heat-upregulated transcriptions of HSP17.8, $H S P 26.7, H S P 70$, and HSP90.1-b1, which play protective 


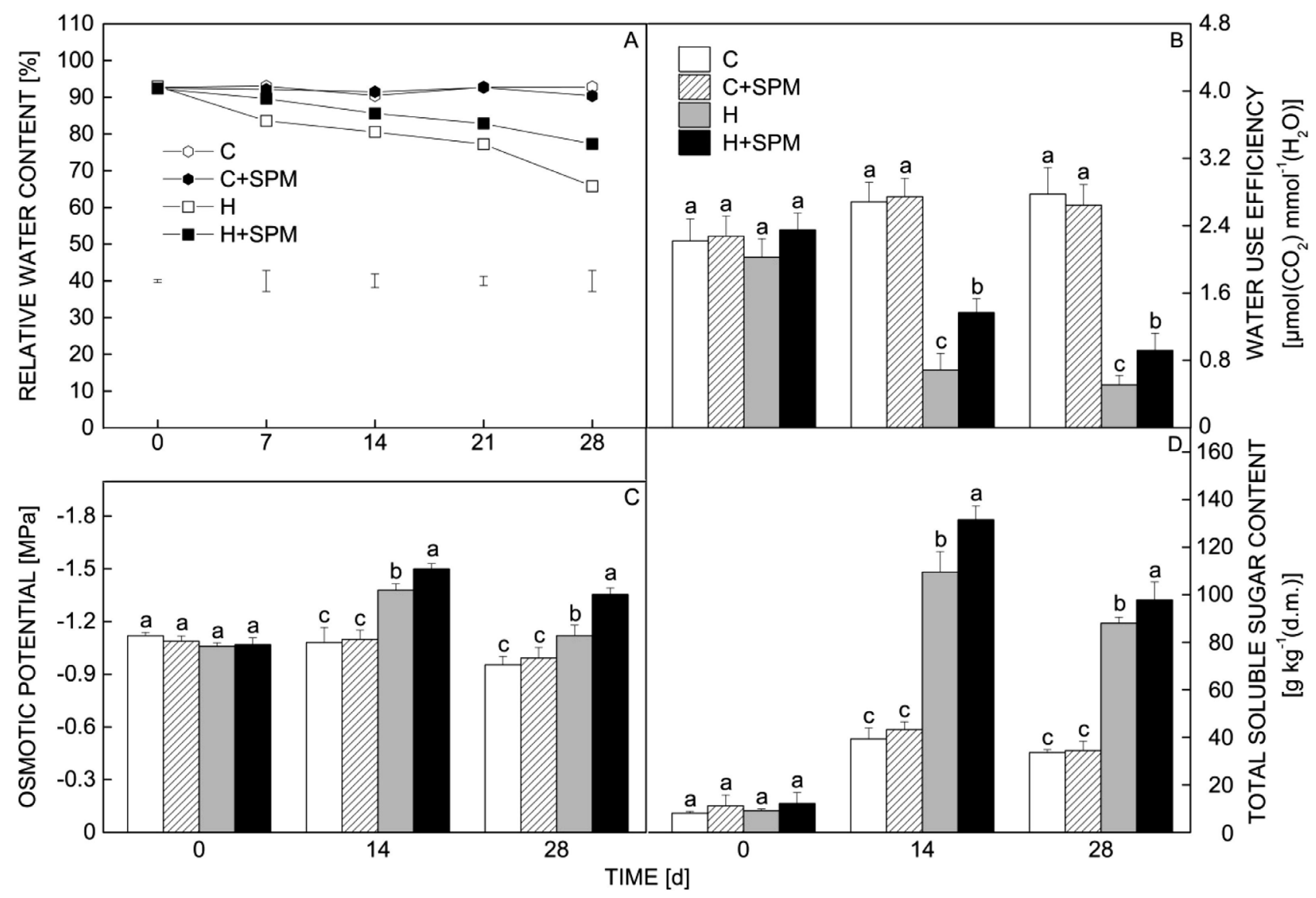

Fig. 7. Changes in relative water content $(A)$, water use efficiency $(B)$, osmotic potential $(C)$, and total soluble sugar $(D)$ in leaves of creeping bentgrass during heat stress. Means \pm SEs, $n=4$. Different letters above columns indicate significant differences among treatments based on the least significant difference $(P \leq 0.05)$ on a given day. C - control, C+SPM - control plus SPM application, $\mathrm{H}$ - heat stress, H+SPM - heat stress plus SPM application.

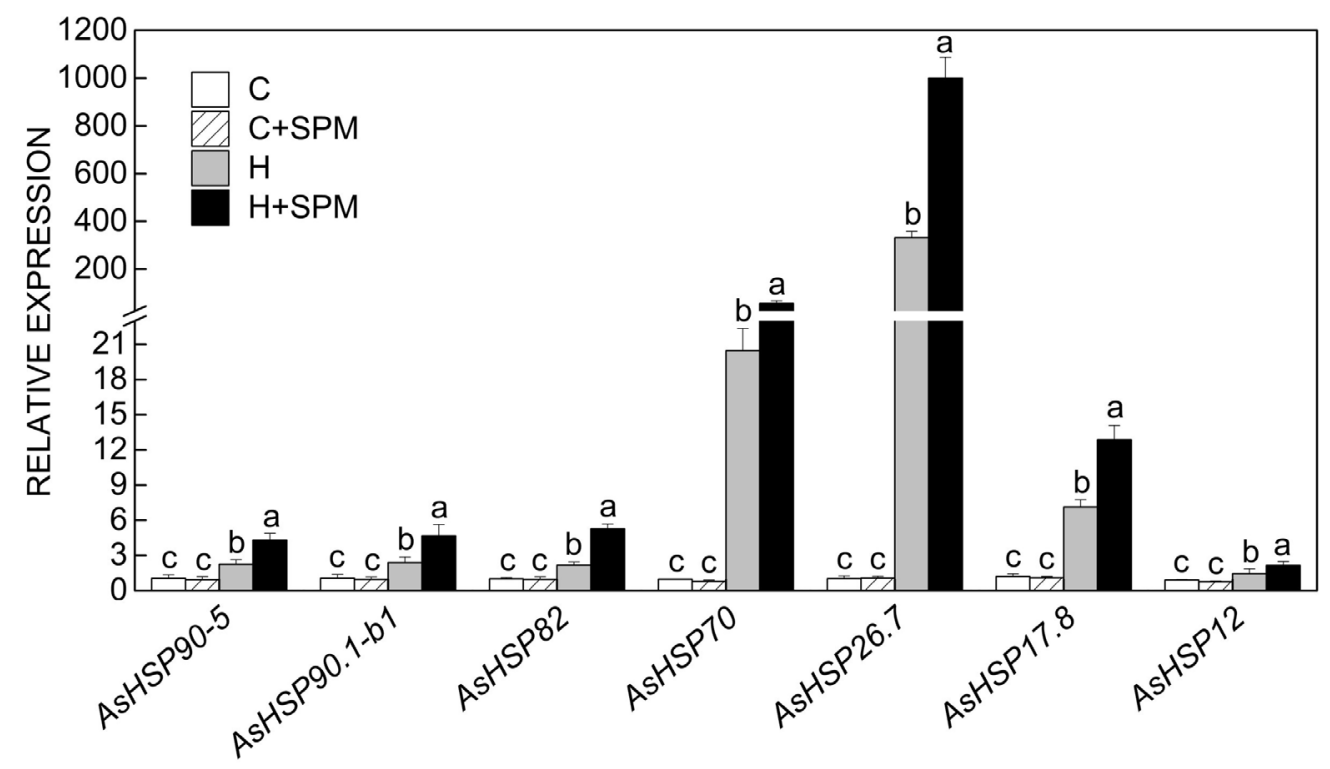

Fig. 8. Changes in transcriptions of genes encoding heat shock proteins (HSPs) in leaves of creeping bentgrass on $28^{\text {th }} \mathrm{d}$. Means \pm SEs, $n=4$. Different letters above columns indicate significant differences among treatments based on the least significant difference at $P \leq 0.05$. C - control, C+SPM - control plus SPM application, H - heat stress, H+SPM - heat stress plus SPM application. 
roles in alleviating heat-induced senescence in creeping bentgrass (Liu et al. 2019). In addition, the study of Fu et al. 2014 found that SPM-treated trifoliate orange seedlings could maintain significantly higher HSP70 and HSP90 expressions than untreated seedlings in the beginning of exposure to combined drought and heat stress. Improved thermotolerance of Arabidopsis by overexpressing a SPM synthase gene (SPMS) is positively correlated with significant increase in SPM content and the expression of HSP90, HSP70, HSP26.5, HSP18.2, and HSP17.4 (Sagor et al. 2013). In our current study, the application of SPM further significantly upregulated the heat-induced HSP90-5, HSP90.1-b1, HSP82, HSP70, HSP26.7, HSP17.8, and HSP12 expressions in creeping bentgrass, which could help to maintain normal synthesis and functions of proteins contributing to the alleviation of heat-induced senescence.

In conclusion, persistent high temperature caused severe oxidative damage and significant decreases in Chl content, photosynthetic efficiency, and water content leading to premature senescence in creeping bentgrass. The improvement of endogenous SPD and SPM induced by SPM application could alleviate heat stress damage to creeping bentgrass through maintaining higher $\mathrm{Chl}$ content and net photosynthetic rate, promoting antioxidant enzyme activities and osmotic adjustment ability, and increasing the expression of heat shock protein genes, thereby delaying heat-induced leaf senescence. These findings reveal the important role of PAs in regulating senescence in perennial plants exposed to high temperature.

\section{References}

Arnon, D.I.: Copper enzymes in isolated chloroplasts. Polyphenoloxidase in Beta vulgaris. - Plant Physiol. 24: 1-15, 1949.

Barrs, H.D., Weatherley, P.E.: A re-examination of the relative turgidity technique for estimating water deficits in leaves. Aust. J. biol. Sci. 15: 413-428, 1962.

Bian, H.W., Wang, J.H., Lin, W.Q., Ning, H., Zhu, M.Y.: Accumulation of soluble sugars, heat-stable proteins and dehydrins in cryopreservation of protocorm-like bodies of Dendrobium candidum by the air-drying method. - J. Plant Physiol. 159: 1139-1145, 2002.

Blum, A., Ebercon, A.: Cell membrane stability as a measure of drought and heat tolerance in wheat. - Crop Sci. 21: 43-47, 1981.

Camejo, D., Rodríguez, P., Ma, A.M., Dell'Amico, J.M., Torrecillas, A., Alarcón, J.J.: High temperature effects on photosynthetic activity of two tomato cultivars with different heat susceptibility. - J. Plant Physiol. 162: 281-289, 2005.

Chance, B., Maehly, A.C.: Assay of catalases and peroxidases. Methods Enzymol. 2: 764-775, 1955.

Dhindsa, R.: Leaf senescence: correlation with increased levels of membrane permeability and lipid peroxidation and increased levels of superoxide dismutase and catalase. - J. exp. Bot. 32: 93-101, 1981.

Elstner, E.F., Heupel, A.: Inhibition of nitrite formation from hydroxylammoniumchloride: a simple assay for superoxide dismutase. - Anal. Biochem. 70: 616-620, 1976.

Fu, X.Z., Xing, F., Wang, N.Q., Peng, L.Z., Chun C.P., Cao L.,
Ling L.L., Jiang C.L.: Exogenous spermine pretreatment confers tolerance to combined high-temperature and drought stress in vitro in trifoliate orange seedlings via modulation of antioxidative capacity and expression of stress-related genes. - Biotechnol. Biotechnol. Equipment. 28: 192-198, 2014.

Giannopolitis, C.N., Ries, S.K.: Superoxide dismutases: I. Occurrence in higher plants. - Plant Physiol. 59: 309-314, 1977.

Giles, K.L., Cohen, D., Beardsell, M.F.: Effects of water stress on the ultrastructure of leaf cells of sorghum bicolor. - Plant Physiol. 57: 11-14, 1976.

Gill, S.S., Tuteja, N.: Reactive oxygen species and antioxidant machinery in abiotic stress tolerance in crop plants. - Plant Physiol. Biochem. 48: 909-930, 2010.

Graham, I.A., Smith, L.S.M.: Induction of malate synthase gene expression in senescent and detached organs of cucumber. Plant Cell 4: 349-357, 1992.

Haba, P.D.L., Mata, L.D.L., Molina, E., Agueera, E.: High temperature promotes early senescence in primary leaves of sunflower (Helianthus annuus L.) plants. - Can. J. Plant. Sci. 94: 659-669, 2014.

Hamdani, S., Gauthier, A., Msilini, N., Carpentier, R.: Positive charges of polyamines protect PSII in isolated thylakoid membranes during photoinhibitory conditions. - Plant Cell Physiol. 52: 866-873, 2011.

Haslbeck, M.: sHsps and their role in the chaperone network. Cell. Mol. Life Sci. 59: 1649-1657, 2002.

Hoagland, D.R., Arnon, D.I.: The water culture method for growing plants without soil. - Calif. Agr. Exp. Sta. Circular 347: 357-359, 1950.

Huang, B.R., Xu, C.P: Identification and characterization of proteins associated with plant tolerance to heat stress. - J. integr. Plant Biol. 50: 1230-1237, 2008.

Jespersen, D., Zhang, J., Huang, B.R.: Chlorophyll loss associated with heat-induced senescence in bentgrass. - Plant Sci. 249: 1-12, 2016.

Jiang, C.H., Xu, J.Y., Zhang, H., Zhang, X., Ming, F.: A cytosolic class I small heat shock protein, RcHSP17.8, of Rosa chinensis confers resistance to a variety of stresses to Escherichia coli, yeast and Arabidopsis thaliana. - Plant Cell Environ. 32: 1046-1059, 2009.

Jibran, R., Hunter, D., Dijkwel, P.: Hormonal regulation of leaf senescence through integration of developmental and stress signals. - Plant mol. Biol. 82: 547-561, 2013.

Kim, K.H., Alam, I., Kim, Y.G., Sharmin, S.A., Lee, K.W., Lee, S.H., Lee, B.H.: Overexpression of a chloroplast-localized small heat shock protein OsHSP26 confers enhanced tolerance against oxidative and heat stresses in tall fescue. - Biotechnol. Lett. 34: 371-377, 2012.

Kubik, C., Honig, J., Bonos, S.A.: Characterization of 215 simple sequence repeat markers in creeping bentgrass (Agrostis stolonifera L.). - Mol. Ecol. Resour. 11: 872-876, 2011.

Kumar, S., Gupta, D., Nayyar, H.: Comparative response of maize and rice genotypes to heat stress: status of oxidative stress and antioxidants. - Acta Physiol. Plant. 34: 75-86, 2012.

Kusano, T., Yamaguchi, K., Berberich, T., Takahashi, Y.: The polyamine spermine rescues Arabidopsis from salinity and drought stresses. - Plant Signal. Behav. 2: 251-252, 2007.

Li, S., Cui, L., Zhang, Y., Wang, Y., Mao, P.: The variation tendency of polyamines forms and components of polyamine metabolism in Zoysiagrass (Zoysia japonica Steud.) to salt stress with exogenous spermidine application. - Front. Physiol. 8: 208, 2017.

Li, Z., Jing, W., Peng, Y., Quan, X., Xiao, Z.: Spermine alleviates drought stress in white clover with different resistance by influencing carbohydrate metabolism and dehydrins synthesis. 
- PLoS ONE 10: e0120708, 2015b.

Li, Z., Zhang, Y., Zhang, X., Peng, Y., Merewitz, E., Ma, X., Huang, L., Yan, Y.: The alterations of endogenous polyamines and phytohormones induced by exogenous application of spermidine regulate antioxidant metabolism, metallothionein and relevant genes conferring drought tolerance in white clover. - Environ. exp. Bot. 124: 22-38, 2016.

Li, Z., Zhou, H., Peng, Y., Zhang, X., Ma, X., Huang, L., Yan, Y.: Exogenously applied spermidine improves drought tolerance in creeping bentgrass associated with changes in antioxidant defense, endogenous polyamines and phytohormones. - Plant Growth Regul. 76: 71-82, 2015a.

Liu, T., Liu, Z., Li, Z., Peng, Y., He, L.: Regulation of heat shock factor pathways by $\gamma$-aminobutyric acid (GABA) associated with thermotolerance of creeping bentgrass. - Int. J. mol. Sci. 20: 4713-4730, 2019.

Livak, K.J., Schmittgen, T.D.: Analysis of relative gene expression data using real-time quantitative PCR and the 2 $\triangle \Delta \mathrm{CT}$ method. - Methods 25: 402-408, 2001.

Moskova, I., Todorova, D., Alexieva, V., Segiev, I.: Protective effect of hydrogen peroxide against paraquat toxicity in young pea plants: possible role of endogenous polyamines. - Amer. J. Plant Sci. 5: 3408-3416, 2014.

Mostofa, M.G., Yoshida, N., Fujita, M.: Spermidine pretreatment enhances heat tolerance in rice seedlings through modulating antioxidative and glyoxalase systems. - Plant Growth Regul. 73: 31-44, 2014.

Murkowski, A.: Heat stress and spermidine: effect on chlorophyll fluorescence in tomato plants. - Biol. Plant. 44: 53-57, 2001.

Nahar, K., Hasanuzzaman, M., Alam, M.M., Rahman, A., Mahmud, J.A., Suzuki, T., Fujita, M.: Insights into spermineinduced combined high temperature and drought tolerance in mung bean: osmoregulation and roles of antioxidant and glyoxalase system. - Protoplasma 254: 445-460, 2017.

Nakano, Y., Asada, K.: Hydrogen peroxide is scavenged by ascorbate-specific peroxidase in spinach chloroplasts. - Plant Cell Physiol. 22: 867-880, 1980.

Perez-Amador, M.A., Leon, J., Green, P.J., Carbonell, J.: Induction of the arginine decarboxylase ADC2 gene provides evidence for the involvement of polyamines in the wound response in Arabidopsis. - Plant Physiol. 130: 1454-1463, 2002.

Puyang, X.H., An, M.Y., Xu, L.X., Han, L.B., Zhang, X.Z.: Protective effect of exogenous spermidine on ion and polyamine metabolism in Kentucky bluegrass under salinity stress. - Hort. environ. Biotech. 57: 11-19, 2016.

Ramos, R.M., Valente, I.M., Rodrigues, J.A.: Analysis of biogenic amines in wines by salting-out assisted liquid-liquid extraction and high-performance liquid chromatography with fluorimetric detection. - Talanta 124: 146-151, 2014.

Sagor, G.H.M., Berberich, T., Takahashi, Y., Niitsu, M.: The polyamine spermine protects Arabidopsis from heat stress- induced damage by increasing expression of heat shockrelated genes. - Transgenic Res. 22: 595-605, 2013.

Sanchez-Rodriguez, E., Romero, L., Ruiz, J.M.: Accumulation of free polyamines enhances the antioxidant response in fruits of grafted tomato plants under water stress. - J. Plant Physiol. 190: 72-78, 2016.

Schramm, F., Ganguli, A., Kiehlmann, E., Englich, G., Walch, D., Koskull-Döring, P.V.: The heat stress transcription factor HsfA2 serves as a regulatory amplifier of a subset of genes in the heat stress response in Arabidopsis. - Plant mol. Biol. 60: 759-772, 2006.

Shukla, V., Ma, Y., Merewitz, E.B: Creeping bentgrass responses to drought stress and polyamine application. - J. amer. Soc. hort. Sci. 140: 102-107, 2015.

Sun, L., Liu, Y., Kong, X., Zhang, D., Pan, J., Zhou, Y., Wang, L., Li, D., Yang, X.: ZmHSP16.9, a cytosolic class I small heat shock protein in maize (Zea mays), confers heat tolerance in transgenic tobacco. - Plant Cell Rep. 31: 1473-1484, 2012.

Timperio, A.M., Egidi, M.G., Zolla, L.: Proteomics applied on plant abiotic stresses: role of heat shock proteins (HSP). - J. Proteomics 71: 391-411, 2008.

Todorova, D., Katerova, Z., Shopova, E., Jodinskiene, M., Sergiev, I.: Responses of pea plants to heat stress and spermine treatment. - Zemdirbyste 103: 99-106, 2016.

Tsukaguchi, T., Fukamachi, H., Ozawa, K., Takeda, H., Suzuki, K., Egawa, Y.: Diurnal change in water balance of heattolerant snap bean (Phaseolus vulgaris) cultivar and its association with growth under high temperature. - Plant Prod. Sci. 8: 375-382, 2005.

Velikova, V., Yordanov, I., Edreva, A.: Oxidative stress and some antioxidant systems in acid rain-treated bean plants: protective role of exogenous polyamines. - Plant Sci. 151: 59-66, 2000.

Yamaguchi, K., Takahashi, Y., Berberich, T., Imai, A., Miyazaki, A., Takahashi, T., Michael, A., Kusano, T.: The polyamine spermine protects against high salt stress in Arabidopsis thaliana. - FEBS Lett. 580: 6783-6788, 2006.

Yamaguchi, K., Takahashi, Y., Berberich, T., Imai, A., Takahashi, T., Michael, A.J., Kusano, T.: A protective role for the polyamine spermine against drought stress in Arabidopsis. Biochem. biophys. Res. Commun. 352: 486-490, 2007.

Zhang, J., Shi, Y., Zhang, X.Z., Du, H.M., Xu, B., Huang, B.R.: Melatonin suppression of heat-induced leaf senescence involves changes in abscisic acid and cytokinin biosynthesis and signaling pathways in perennial ryegrass (Lolium perenne L.). - Environ. exp. Bot. 138: 36-45, 2017.

Zhang, J., Xing, J., Lu, Q.Y., Yu, G.H., Xu, B., Huang, B.R.: Transcriptional regulation of chlorophyll-catabolic genes associated with exogenous chemical effects and genotypic variations in heat-induced leaf senescence for perennial ryegrass. - Environ. exp. Bot. 167: 103858, 2019.

Zhu, X., Shen, H.L.: Effect of high temperature stress on cell membrane in celery seedlings. - North. Hort. 7: 16-20, 2014. 